\title{
Contribuições da Psicologia Histórico-Cultural e da Pedagogia Histórico-Crítica à superação da visão neoliberal de aprendizagem de língua inglesa
}

\author{
Contributions of Historical-Cultural Psychology and Historical-Critical Pedagogy to \\ overcoming the neoliberal view of English language learning \\ Letícia Berneira CARDOZO* \\ Universidade Federal de Santa Catarina (UFSC)
}

\begin{abstract}
RESUMO: O ensino de língua inglesa no cenário brasileiro está envolto em uma perspectiva neoliberal, que transforma o ensino em um bem material e seus aprendizes em consumidores. Entretanto, faz-se necessário repensar o ensino da língua inglesa, de modo a propiciar aos aprendizes as ferramentas necessárias à emancipação dos sujeitos nesse cenário globalizante, oferecendo meios de humanização. Portanto, este artigo busca na Psicologia Histórico-Cultural elementos que corroborem para se pensar a aprendizagem de língua inglesa em termos de desenvolvimento humano, isto é, o quanto aprender uma língua estrangeira pode contribuir para que os sujeitos se reconheçam como parte integrante da sociedade, capazes de agir e transformar suas próprias realidades. Ao mesmo tempo, busca-se na Pedagogia HistóricoCrítica motivações para se desvencilhar dessas pedagogias acríticas que assolam o ensino de línguas, propondo assim, um olhar de luta, de comprometimento com um ensino humanizador.
\end{abstract}

PALAVRAS-CHAVE: Psicologia Histórico-Cultural; Pedagogia Histórico-Crítica; Aprendizagem de língua inglesa; Formação do ser social

\begin{abstract}
English language teaching in the Brazilian scenario is surrounded by a neoliberal perspective that transforms learning into goods and its learners into consumers. However, it is necessary to rethink the teaching of the English language, in order to provide learners the proper tools for emancipation in this globalizing scenario, besides offering means of humanization. Therefore, this paper seeks to find in the Historical-Cultural Psychology elements that corroborate to think English language learning in terms of human development, that is, how much a foreign language can contribute for the subjects to recognize themselves as an integral part of society, capable of acting and transforming their own realities. At the same time, this study seeks to find in the Historical-Critical Pedagogy motivations to disentangle from these acritical pedagogies that plague language teaching, thus proposing struggles and commitment to a humanizing teaching.
\end{abstract}

KEYWORDS: Cultural-Historical Psychology; Historical-Critical Pedagogy; English language learning; Formation of social being

\footnotetext{
* Doutoranda no Programa de Pós-Graduação em Linguística da Universidade Federal de Santa Catarina (UFSC). E-mail: leticiacardozo1@yahoo.com.br
}

Revista Moara, n. 54, ago-dez 2019 ISSN: 0104-0944

Recebido em 30/10/2019

Avaliado em 24/11/2019 


\section{Introdução}

Os últimos quarenta anos têm se revelado um período de grandes transformações no campo político, econômico e social. Com o término da Guerra Fria, temos presenciado o discurso neoliberal da economia política mundial invadindo o cenário educacional e atribuindo papeis estratégicos ao ensino. De acordo com Marrach (1996), essa nova configuração social exige um projeto formativo humano que carregue as seguintes características:

1. Atrelar a educação escolar à preparação para o trabalho e a pesquisa acadêmica ao imperativo do mercado ou às necessidades da livre iniciativa. Assegurar que o mundo empresarial tem interesse na educação porque deseja uma força de trabalho qualificada, apta para a competição no mercado nacional e internacional. [...] 2. Tornar a escola um meio de transmissão dos seus princípios doutrinários. O que está em questão é a adequação da escola à ideologia dominante. [...] 3. Fazer da escola um mercado para os produtos da indústria cultural e da informática, o que, aliás, é coerente com idéia de fazer a escola funcionar de forma semelhante ao mercado, mas é contraditório porque, enquanto, no discurso, os neoliberais condenam a participação direta do Estado no financiamento da educação, na prática, não hesitam em aproveitar os subsídios estatais para divulgar seus produtos didáticos e paradidáticos no mercado escolar. (MARRACH, 1996, p. 46-48).

Marrach (1996) afirma que o projeto neoliberal se insere na educação, visando, majoritariamente, a relação entre educação e formação de mão-de-obra capacitada para o desenvolvimento econômico do país. A democratização dos saberes passa a ser regulada e comercializada em torno de uma formação focada em valores como sucesso, qualidade, produtividade, competividade, competências e, consequentemente, o lucro.

Se para Saviani (2013), à educação cabe possibilitar que "as novas gerações incorporem os elementos herdados de modo que se tornem elementos ativos no processo de desenvolvimento ativo e transformação das relações sociais" (SAVIANI, 2013, p.121), a visão neoliberal de educação se coloca como uma formação alienadora, acrítica e incapaz de propiciar o processo de humanização dos sujeitos. Esse ideário acaba por negar a educação como "condição de direito social e transformando-a em uma possibilidade de consumo individual” (GENTILI, 1998, p. 14). Tem-se aí, uma educação focada nas competências. Essas habilidades individuais trazem a tônica do 
diferencial humano, que se fundamentarão na meritocracia e no esforço individual dos cidadãos.

Dentro dessa perspectiva neoliberal de educação, o ensino de língua inglesa ${ }^{1}$ parece destacar-se na compra de tal lógica, uma vez que a aprendizagem de uma língua estrangeira, em grande parte das escolas públicas e privadas, bem como institutos de idiomas prioriza o desenvolvimento de habilidades e competências, com vistas à instrumentalização para o mercado de trabalho. Aprender uma nova língua é motivo para ascender socioeconomicamente e não um elemento possibilitador da emancipação e humanização dos sujeitos.

Frente à esta problemática que se impõe, este artigo busca na Psicologia Histórico-Cultural elementos que corroborem para se pensar a aprendizagem da língua inglesa em termos de desenvolvimento humano, isto é, o quanto aprender uma nova língua pode contribuir para que os sujeitos se reconheçam como parte integrante da sociedade, capazes de agir e transformar suas próprias realidades. Ao mesmo tempo, busca-se na Pedagogia Histórico-Crítica motivações para se desvencilhar dessas pedagogias acríticas que assolam o ensino de línguas estrangeiras, propondo assim, um olhar de luta, de comprometimento com um ensino humanizador.

A metodologia deste trabalho está assentada no materialismo histórico-dialético. Conforme Frigotto (1991, p. 77):

\footnotetext{
$\mathrm{Na}$ perspectiva materialista histórica, o método está vinculado a uma concepção de realidade, de mundo e de vida no seu conjunto. A questão da postura, neste sentido, antecede o método. Este constitui-se numa espécie de mediação no processo de apreender, revelar e expor a estruturação, o desenvolvimento e transformação dos fenômenos sociais.
}

Na próxima seção deste artigo, há o empenho de trazer um contexto histórico que justifique a ascensão da língua inglesa no cenário mundial e como a perspectiva neoliberal distorce a importância de se aprender um novo idioma. Este artigo ainda revela seu caráter de pesquisa bibliográfica, uma vez que na seção seguinte, a Psicologia Histórico-Cultural é discutida com vistas a ampliar a visão simplista de ensino voltada à

\footnotetext{
${ }^{1}$ Este artigo parte das discussões de aprendizagem de língua inglesa como língua estrangeira.
} 
lógica mercadológica, abordando, assim, como se dá o desenvolvimento humano mediado pela linguagem.

Logo em seguida, a próxima seção busca na Pedagogia Histórico-Crítica elementos para se repensar um ensino de línguas que se compromete com processos formativos de humanização, a emancipação dos sujeitos e com a criticidade para lidar com os discursos hegemônicos que nos interpelam. Na seção subsequente, há a tentativa de expor as consequências de se optar por um ensino humanizador ou alienador, a fim de que educadores possam se conscientizar da agenda educacional com que desejam se comprometer.

Por fim, faz-se uma retomada do artigo e os encaminhamentos finais.

\section{Da ascensão da língua inglesa aos tempos neoliberais}

Esta seção busca fazer uma breve contextualização histórica que nos possibilita compreender as circunstâncias políticas, econômicas, culturais e sociais que elevaram a língua inglesa ao status de língua global. Além disso, busca-se problematizar como os tempos neoliberais condicionam a sociedade ao consumo da língua.

De acordo com Crystal (2012), a língua inglesa chegou à Inglaterra pelo norte europeu por volta do século $\mathrm{V}$ e, paulatinamente, sua expansão se deu pelas ilhas britânicas de Cúmbria, Cornualha, País de Gales e Escócia. Entretanto, os relatos históricos datam a ascensão da língua inglesa a partir das viagens pioneiras feitas às Américas, à Ásia e à Antípodas até o século XIX.

A língua inglesa ganha seu caráter global a partir da disputa direta entre Espanha e Portugal pelos produtos chineses e indianos. Com a necessidade de explorar, de dominar outros mercados e de tornar-se cada vez mais competitiva, a Grã-Bretanha se insere numa lógica industrial, promovendo a mecanização de suas atividades, com vistas a alcançar maior produtividade, redução de custos e, prioritariamente, o aumento dos lucros. Consequentemente, essa revolução caracterizada pela mudança agrária à industrial, gera tecnologias, maquinários e equipamentos necessários à fabricação de produtos. Novas palavras são necessárias para descrever esses novos instrumentos. 
Logo, esse novo vocabulário se dá na língua que domina o setor daquele momento, a língua inglesa.

Segundo Arrighi (1996), países como Alemanha, Japão e Estados Unidos também investiram no setor industrial. Entretanto, a alta competividade entre mercados, associadas às barreiras protecionistas de outras nações leva o regime de acumulação da Grã-Bretanha a sofrer impactos econômicos, caracterizando assim, a Grande Depressão (1929-1939). Além disso, em um tempo muito aproximado, ocorre a Segunda Guerra Mundial, que enfraquece a economia e a política britânica. Enquanto a Europa tenta se reconstruir da Segunda Guerra Mundial, os Estados Unidos passam a usufruir de seus recursos naturais disponíveis em seu próprio território, ganhando assim, os bons olhos das grandes corporações. Para Arrighi (1996):

\begin{abstract}
como em todos os casos anteriores de enriquecimento e conquista de poder prodigiosos, em meio a um crescente caos sistêmico, o grande salto à frente da riqueza e poder norte-americanos entre 1915 e 1945 foi, primordialmente, uma expressão da renda de proteção de que o país desfrutava, numa posição singularmente privilegiada na configuração espacial da economia mundial capitalista. Quanto mais turbulento e caótico se tornava o sistema mundial, maiores os benefícios auferidos pelos Estados Unidos, em virtude de suas dimensões continentais, sua posição insular e seu acesso direto aos dois grandes oceanos da economia mundial. (ARRIGHI, 1996, p. 284-285)
\end{abstract}

Todos esses avanços estadunidenses são mediados e difundidos através da língua inglesa. Segundo Truchot (1990), a mídia impressa e eletrônica, associada também aos meios de entretenimento como cinema, disco e programas televisionados são os principais meios propagadores da cultura americana. Nesse sentido, para o autor, "as mídias propagam em inglês a reprodução da realidade do mundo contemporâneo" (TRUCHOT, 1990, p. 173). Cabe ressaltar ainda que a informática que possibilitou o acesso rápido a qualquer tipo de informação também contribui para que a língua inglesa alcançar ainda mais territórios.

Fiori (2007) afirma que os Estados Unidos deram o grande salto a partir do final da União Soviética e da Guerra Fria, em 1991, quando o capitalismo passa a caminhar a passos largos para dominar a economia das nações. A expansão capitalista associada a difundida cultura norte-americana sinaliza para o que o sociólogo Ritzer (1993) aponta 
como a McDonaldização da Sociedade ${ }^{2}$, isto é, a homogeneização das ideias e interesses, por meio de processos padronizadores da cultura. Ser parte de uma sociedade globalizada, difunde a ideia de que todo cidadão pertence ao mundo. Entretanto, tais discursos, que se dizem neutros, inclusivos e de acolhimentos, escondem "um subproduto importante e necessário - uma cidadania despolitizada, marcada pela apatia e pelo cinismo" (MCCHESNEY, 2002, p.4)

Cabe ressaltar que essa visão capitalista e de globalização de ideias e interesses também está subjacente à forma como o ensino de língua inglesa é concebida no contexto brasileiro. Paulatinamente, o ensino de outras línguas como o espanhol, italiano, alemão ou francês são apagadas dos currículos, em nome de uma cômoda ideia de que a língua inglesa é o maior meio de difusão da ciência e da tecnologia. O ensino da língua passa a ser vendido como garantia de um futuro melhor, maior competividade no mercado de trabalho e melhores possibilidades de ascensão social. A língua ganha um caráter instrumental, voltado a um fim específico: atender às demandas do mercado trabalhista. Nesse sentido, percebe-se que há um esvaziamento, uma visão muito simplista da dimensão educacional e do poder de humanização que o conhecimento de outras línguas pode oferecer à formação dos indivíduos.

Além disso, o ensino brasileiro, em geral, está envolto em estratégias neoliberais. Segundo Gentili (1996, p.20), “a grande operação estratégica do neoliberalismo consiste em transferir a educação da esfera política para a esfera do mercado, questionando assim seu caráter de direito e reduzindo-a a sua condição de propriedade". Essa visão ganha ainda mais notoriedade dentro do ensino de língua inglesa como língua estrangeira, onde discursos do senso comum naturalizam a ideia de que na escola pública não é um espaço possível para aprendizagem da língua inglesa. A omissão do estado em fornecer uma educação de qualidade, em fornecer materiais, infraestrutura, condições adequadas ao ensino e formação docente contínua abre espaços para que o ensino da língua vire mercadoria em institutos de idiomas e em escolas bilíngues.

É neste quadro que se reconceitualiza a noção de cidadania, através de uma revalorização da ação do indivíduo enquanto proprietário, enquanto indivíduo

\footnotetext{
${ }^{2}$ Ritzer, na obra "The McDonaldization of Society" (1993), levanta uma reflexão de como os princípios de uma famosa rede de fast food estão homogeneizando culturas.
}

Revista Moara, n. 54, ago-dez 2019 ISSN: 0104-0944 
que luta por conquistar (comprar) propriedades mercadorias de diversa índole, sendo a educação uma delas. O modelo de homem neoliberal é o cidadão privatizado, o interpreneur, o consumidor. (GENTILI, 1996, p. 2021).

No cenário que se põe, a educação deixa de ser um direito universal. Aprender uma língua estrangeira é razão para construção de privilégios que só ampliam a verticalidade da elite burguesa e favorecem a manutenção do status quo. Esses sujeitos que são deixados às margens da sociedade acabam por ser excluídos da possibilidade de acesso aos conhecimentos historicamente acumulados e, consequentemente, da possibilidade de emancipação humana.

Portanto, a próxima seção busca na Psicologia Histórico-Cultural elementos para suportar a ideia de que aprender um novo sistema linguístico é uma forma de promover o desenvolvimento humano, com vistas à superação da visão neoliberal de aprendizagem de língua inglesa.

\section{Repensando a aprendizagem de língua inglesa por meio da Psicologia Histórico-Cultural}

A Psicologia Histórico-Cultural teve as suas origens nos primórdios do século XX. Edificada por Lev Semyonovich Vigotski, tal perspectiva sobre o desenvolvimento humano se propôs analisar a raiz das psicologias anteriores, de modo a contrapor-se a essas perspectivas de caráter biologizantes e superá-las por incorporação. Nesse sentido, a Psicologia Histórico-Cultural instaura o cerne do desenvolvimento humano numa perspectiva histórico-social, segundo a qual, “o avanço em termos da personalidade terá seus limites dados pelo avanço da sociedade" (DUARTE, 2013, p.22).

Assentado no materialismo histórico-dialético ${ }^{3}$, Vigotski parte de uma premissa de que o desenvolvimento do psiquismo humano não se dá de forma imediata, mecânica ou inata. Para o psicólogo, o desenvolvimento é fruto de uma participação ativa dos sujeitos, que estão inseridos numa cultura histórica. Para Vigotski \& Luria (1996):

\footnotetext{
${ }^{3} \mathrm{O}$ materialismo histórico-dialético considera o homem como um sujeito histórico. Ao se apropriar da cultura historicamente produzida, modifica o que já foi elaborado num processo dialético de objetivações e apropriações.
}

Revista Moara, n. 54, ago-dez 2019 ISSN: 0104-0944

Recebido em 30/10/2019

Avaliado em 24/11/2019 
Se desejarmos estudar a psicologia do homem cultural adulto, devemos ter em mente que ela se desenvolveu como resultado de uma evolução complexa que combinou pelo menos três trajetórias: a da evolução biológica desde os animais até o ser humano, a da evolução histórico-cultural, que resultou na transformação gradual do homem primitivo no homem cultural moderno, e ao desenvolvimento individual de uma personalidade específica (ontogênese), com o que um pequeno recém-nascido atravessa inúmeros estágios, tornando-se um escolar e a seguir um homem adulto cultural (Vigotski \& Luria, 1996, p. 151).

Ao fazer parte de um contexto, o sujeito necessita se apropriar de diversos objetos/elementos para garantir suas condições de existência. Ao objetivar o conhecimento historicamente produzido, os indivíduos se apropriam e criam possibilidades de transformar o espaço em que vivem. Isso significa que o desenvolvimento do psiquismo humano tem sua explicação fundamental voltada à atividade vital humana, ou seja, na categoria trabalho discutida por Marx. Segundo Duarte (1999):

\begin{abstract}
A atividade vital é a base a partir da qual cada membro de uma espécie reproduz a si próprio enquanto ser singular e, em consequência, reproduz a própria espécie. No caso do ser humano, a mera sobrevivência física dos indivíduos e sua reprodução biológica através do nascimento de seres humanos, assegura a continuidade da espécie biológica, mas não assegura a reprodução do gênero humano, com suas características historicamente constituídas (DUARTE, 1999, p. 28).
\end{abstract}

Para Duarte (1999), a objetivação e a apropriação dos conhecimentos historicamente acumulados pelos indivíduos são elementos fundamentais para garantir a formação do gênero humano, distinguindo-nos, assim, dos animais, que não realizam atividades previamente idealizadas. Sendo assim, o homem se desenvolve por motivações sócio-histórico-culturais. A fim de ilustrar esse processo de objetivação e apropriação, recorro à citação de Marx (1996, p.50):

\footnotetext{
Antes de surgir o alfaiate, o ser humano costurou, durante milênios, pressionado pela necessidade de vestir-se. Mas o casaco, o linho, ou qualquer componente da riqueza material que não seja dado pela natureza, tinha de originar-se de uma especial atividade produtiva, adequada a determinado fim, e que se adapta certos elementos da natureza as necessidades particulares do homem.
}

Para Marx (1996), à medida que o homem satisfaz determinadas necessidades, outras tendem a surgir, de modo a dar continuidade ao processo evolutivo dos seres 
humanos. Portanto, para a Psicologia Histórico Cultural, a atividade exerce forte influência no psiquismo humano, conforme aponta Leontiev (2004):

\begin{abstract}
Pela sua atividade, os homens não fazem senão adaptar-se à natureza. Eles modificam-na na função do desenvolvimento de suas necessidades. Criam os objetos que devem satisfazer às suas necessidades e igualmente os meios de produção destes objetos, dos instrumentos às máquinas mais complexas. Constroem habitações, produzem as suas roupas e os bens materiais. Os progressos realizados na produção de bens materiais são acompanhados pelo desenvolvimento da cultura dos homens (Leontiev, 2004, p. 283)
\end{abstract}

Contudo, para que o ser humano se aproprie do acervo de objetivações que foram produzidas e aprimoradas ao longo da humanidade, o homem invariavelmente é mediado por signos. Segundo Martins (2015, p.45),

os signos são meios auxiliares para a solução de tarefas psicológicas e, analogamente às ferramentas ou aos instrumentos técnicos de trabalho, exigem adaptação do comportamento a eles, do que resulta a transformação psíquica estrutural que promovem. (MARTINS, 2015, p. 45)

Os signos além de fazerem a mediação indireta do homem com o mundo, eles operam "um estímulo de segunda ordem que, retroagindo sobre as funções psíquicas, transforma suas expressões espontâneas, naturais, em expressões volitivas, culturais" (MARTINS, 2015, p.46). Em outras palavras, o signo ao refletir uma determinada realidade, ele também é capaz de produzir diferentes formas de sentido, a depender do contexto em que é empregado. Portanto, o conhecimento do mundo é mediado pelos signos, que são culturalmente determinados.

Segundo Martins (2015), Vigotski compreendia que o papel do signo no comportamento dos indivíduos assumia uma função instrumental. Isso significa que tanto os instrumentos como os signos também abarcavam a concepção de atividade mediadora, isto é, "um tipo de atividade que permite aos que participem dela exercerem entre si, a partir de suas propriedades essenciais, uma influência recíproca da qual depende a consecução do seu objetivo" (MARTINS, 2015, p. 46,47). Essa atividade mediadora seria responsável por provocar as mudanças no desenvolvimento dos indivíduos. Se por um lado o instrumento técnico seria capaz de intermediar as atividades dos seres humanos no âmbito externo e visível da sociedade, transformando 
assim o objeto externo, o signo, por sua vez, poderia ocasionar mudanças na psique dos sujeitos, ou seja, o ser humano se transforma internamente, se humaniza. Para Martins (2015, p.47):

\begin{abstract}
da mesma maneira que o instrumento técnico modifica o processo de adaptação natural determinando as formas de operações de trabalho - o domínio da natureza, o uso dos instrumentos psicológicos modifica radicalmente o desenvolvimento e a estrutura das funções psíquicas, reconstituindo suas propriedades e possibilitando o autodomínio do comportamento. (MARTINS, 2015, p.47)
\end{abstract}

Nesse sentido, a utilização do signo verbal modifica radicalmente $o$ desenvolvimento psíquico, uma vez que o signo permite a formação da "imagem subjetiva da realidade objetiva" (MARTINS, 2015, p.49), isto é, nossas percepções e sensações são responsáveis por criar uma imagem subjetivada da realidade concreta. $\mathrm{O}$ desenvolvimento da linguagem desde a infância, portanto, possibilita a formação do pensamento abstrato e o estabelecimento das relações com os mais variados elementos que circundam os seres humanos. Para Martins (2016, p. 1574):

\begin{abstract}
Apenas a linguagem torna possível a abstração das propriedades, condicionantes, características da situação-problema ou tarefa a ser realizada, permitindo suas formulações sob a forma de ideias, de conceitos e juízos. Ou seja, a linguagem possibilita o raciocínio sistematizado, o exercício intelectual de checagem das conexões entre os objetos e fenômenos da realidade e suas propriedades essenciais. (MARTINS, 2016, p. 1574)
\end{abstract}

Esse nível de abstração, de representação mental do mundo que nos rodeia, representa a fase de internalização, de formação de conceitos, momento em que o ser humano é capaz de converter as relações sincréticas em relações sintéticas (MARTINS, 2015). Assim, a internalização dos signos viabiliza que toda representação mental das imagens se constitua sob a forma de palavras e conceitos. A internalização, portanto, é a passagem de processo interpessoal para um processo intrapessoal.

Além disso, Martins (2015) aponta que o desenvolvimento do pensamento e da linguagem se dá à medida em que ocorre o processo de complexificação de palavras. A autora compreende que a complexificação da palavra se dá pela "transição de correlações mais diretas e imediatas entre objeto e palavra em direção a correlações mais gerais e abstratas" (MARTINS, 2015, p. 50). Nesta perspectiva, insiro a 
importância de se aprender uma língua estrangeira, uma vez que o acesso às novas formas linguísticas pode contribuir para o desenvolvimento da consciência metalinguística dos indivíduos e da interação dialética entre línguas. Vigotski (1987) já sinalizava que a língua estrangeira poderia servir de subsídio para o domínio de formas mais elevadas da língua materna. Para o autor:

\footnotetext{
uma língua estrangeira facilita o aprendizado de formas mais elevadas da língua materna. A criança aprende a ver a sua língua como um sistema específico entre muitos, a conceber os seus fenômenos à luz de categorias mais gerais, e isso leva à consciência de suas operações linguísticas. (VYGOTSKY, 1987, p.94)
}

Em um pensamento conciliatório a Vygotsky (1987), Bohn (2009, p. 176) afirma que "a língua estrangeira muda a relação do aprendiz com a sua língua materna, há a entrada do 'outro' nessa relação. Até certo modo, aprender uma língua estrangeira é fazer uma regressão, voltar ao estado do infans". Nesta perspectiva, compreendo que aprender uma língua estrangeira abre possibilidades para identificar, interpretar e fazer uso das novas palavras como instrumento de interação. Tal ação é possível porque a aprendizagem de uma língua estrangeira incide em processos de generalização, que podem permitir ao aprendiz o desenvolvimento de uma percepção mais ativa para os elementos linguísticos que subjazem as línguas estudadas. Além disso, aprender uma língua estrangeira é uma forma de apropriar-se de um repertório linguístico e cultural, captando os diferentes valores impressos pelos signos. É fazer uso da nova linguagem como forma de empoderamento, de não se deixar dominar por discursos alienadores e que se dizem neutros. É ter autonomia e, acima de tudo, é exercer a tolerância e o respeito sobre o que parece ser distinto.

À guisa de conclusão: esta seção buscou apresentar como o psiquismo humano se desenvolve e transforma os indivíduos. Através das complexas formas culturais e das atividades historicamente produzidas, os seres humanos se objetivam e se apropriam dos conhecimentos historicamente acumulados pela sociedade. Ao se apropriarem desses conhecimentos, os indivíduos criam experiências e desenvolvem outras funções psicológicas. Além disso, buscou-se na Psicologia Histórico-Cultural elementos que justifiquem a importância de se aprender a língua inglesa para além do capital, isto é, buscar a instrumentalização linguística dos sujeitos, de modo que os indivíduos 
reconhecem na dialética das línguas apreendidas, elementos que favoreçam o desenvolvimento pleno e plural dos sujeitos, através de repertórios culturais e linguísticos estendidos.

Na próxima seção, busco através da Pedagogia Histórico-Crítica elementos que ajudem a superar a visão neoliberal presente na educação brasileira, em especial, no ensino de língua inglesa, de modo a conceber que "o conhecimento mais desenvolvido é aquele que permite a objetivação do ser humano de forma cada vez mais universal e livre" (DUARTE, 2016, p.67).

\section{Repensando a aprendizagem de língua inglesa através da Pedagogia Histórico-Crítica}

Tendo em mente que a Psicologia Histórico-Cultural nos permite compreender o desenvolvimento do psiquismo humano, logo, necessitamos de uma educação que propicie a "[...] a aquisição dos instrumentos que possibilitam o acesso ao saber elaborado (ciência), bem como o próprio acesso aos rudimentos desse saber" (SAVIANI, 2008, p. 15). Nesse sentido, buscamos uma educação que corrobore com o desenvolvimento do conhecimento historicamente sistematizado sem perder de vista a formação integral humana. Com isso, urge a necessidade de uma formação humanizadora e igualitária, que atenda a todas as classes trabalhadoras e não apenas os interesses econômicos daqueles que já são privilegiados. Por conta disso, a Pedagogia Histórico-Crítica pode corresponder a esse ideário, uma vez que

[...] centra-se, pois, na igualdade essencial entre os homens. Entende, porém, a igualdade em termos reais e não apenas formais. Busca, pois, converter-se, articulando-se com forças emergentes da sociedade, em instrumento a serviço da instauração de uma sociedade igualitária. Para isso a pedagogia revolucionária, longe de secundarizar os conhecimentos descuidando da sua transmissão, considera a difusão de conteúdos, vivos e atualizados, uma das tarefas primordiais (SAVIANI, 1999, p.73)

Ao buscar a igualdade essencial entre homens, a Pedagogia Histórico-Crítica deixa transparecer seu caráter revolucionário, de luta de classes, criticando de forma contundente a maneira como a escola e a sociedade estão organizadas no sistema 
burguês. Essa luta se faz pertinente, pois, segundo Duarte e Saviani (2012, p. 9), “o domínio do conhecimento é uma das armas que a classe dominante emprega para neutralizar as ações potencialmente revolucionárias”. Logo,

\begin{abstract}
A pedagogia revolucionária situa-se, pois, além da pedagogia da essência e da existência. Supera-as, incorporando suas críticas recíprocas numa proposta radicalmente nova. O cerne dessa novidade radical consiste na superação da crença da crença na autonomia, seja na dependência absoluta da educação em face das condições sociais vigentes (SAVIANI, 1999, p. 65-66)
\end{abstract}

Nesse sentido, essa pedagogia revolucionária vem buscando, desde a década de 70, a superação dos modelos educacionais que ainda deixam seus rastros não-críticos na formação humana brasileira. Assim, a Pedagogia Histórico-Crítica "se diferencia no bojo das concepções críticas; ela diferencia-se da visão crítico-reprodutivista, uma vez que procura articular um tipo de orientação pedagógica que seja crítica sem ser reprodutivista" (SAVIANI, 2013, p. 3). A superação das teorias crítico-reprodutivistas nos permite romper com os interesses do capital, de modo a frear ou minar mecanismos hegemônicos voltados à manutenção do status quo.

Consequentemente, a educação só pode ser, de fato, humanizadora, se desenvolvida com base na história e historicidade dos educandos, assumindo, assim, o papel de socializar os conhecimentos historicamente acumulados, sistematizando-os e instrumentalizando os sujeitos para que eles possam agir e incidir na realidade concreta. Desta forma,

[...] o trabalho educativo é o ato de produzir direta e intencionalmente, em cada indivíduo singular, a humanidade que é produzida histórica e coletivamente pelo conjunto dos homens. Assim, o objeto da educação diz respeito, de um lado, a identificação dos elementos culturais que precisam ser assimilados pelos indivíduos da espécie humana para que eles se tornem humanos e, de outro lado e concomitantemente, à descoberta das formas mais adequadas para atingir esse objetivo (SAVIANI, 2012, p.13).

No âmbito de ensino e aprendizagem de línguas estrangeira, em especial, a língua inglesa, o que se percebe são visões muito dicotomizadas. De um lado, temos materiais de ensino que prezam pelo ensino mecanizado e reprodutor de estruturas fonéticas, gramaticais, sintáticas e morfológicas, ancorados em premissas de que os 
alunos que estudam inglês como língua estrangeira, distantes dessa cultura linguística, devem majoritariamente saber estruturar a língua. Do outro lado, tem-se a cultura do "aprender a aprender", isto é, "[...] o processo educativo comum em um processo de interação entre significados subjetivos e individuais em oposição à transmissão de um saber objetivo socialmente construído" (DUARTE, 2012, p.108).

Para Duarte (2012), tal pedagogia coloca o aprendiz como protagonista da sua própria educação, uma vez que permite ao aluno ficar "à vontade" para descobrir de forma autônoma o funcionamento de uma língua. O aprendiz, dentro dessa pedagogia do "aprender a aprender" torna-se responsável por perceber, buscar explicações, entender, saber fazer uso e associações de uma língua que pouco ouviu, leu, falou ou sequer escreveu. E, no final das contas, tais pedagogias, abordagens ou metodologias mágicas para se aprender línguas estrangeiras restringem o acesso aos conhecimentos e levantam barreiras da exclusão e da desigualdade.

Além disso, é notório que a cultura do ensino de língua inglesa gira em torno do preço, de produtos, de aquisição simbólica de status e de competividade. Institutos de Idiomas, através de jargões neoliberais, vendem milhares de sonhos: "A escolha de quem é apaixonado pelo sucesso", "Você faz o seu caminho", "Você, cidadão do mundo”. Para medir o grau de sucesso propiciado pela língua, indivíduos se submetem à provas de proficiência que determinam seus níveis de conhecimento. Certificações conferem a competência dos sujeitos para determinados fins. Se insatisfeitos com as competências de comunicação, os aprendizes podem comprar pacotes didáticos com apostilas, $C d s$ e outros recursos multimídias que poderão garantir o desenvolvimento de novas habilidades.

Diante da problemática levantada neste estudo, busco na Pedagogia HistóricoCrítica e a Psicologia Histórico-Cultural elementos que permitam superar essa visão neoliberal e excludente de ensino de línguas estrangeiras. Ao assumir que a aquisição dos conhecimentos historicamente construídos pela humanidade são elementos essenciais para instrumentalizar os indivíduos, abrimos possibilidades para o desenvolvimento pleno dos sujeitos, de modo a projetar na sociedade as transformações consequentes da humanização. Para tanto, Mészáros (2005) nos aponta para a seguinte questão:

Revista Moara, n. 54, ago-dez 2019 ISSN: 0104-0944 
[...] mudar essas condições exige uma intervenção consciente em todos os domínios e em todos os níveis da nossa existência individual e social. É por isso que, segundo Marx, os seres humanos devem mudar completamente as condições de sua existência industrial e política, e, consequentemente, toda a sua maneira de ser. (2005, p.59)

A escola não é lócus de formação unicamente voltada ao mercado de trabalho. Aprender uma língua estrangeira não deve ser encarado, majoritariamente, como qualificação profissional. Nessa lógica neoliberal, não há espaço para transcender, não há espaço para elaboração e reflexão sobre o conhecimento humano. Portanto, comprometer-se com a transformação da sociedade é, ao mesmo tempo, preocupar-se com a prática educativa crítica, emancipadora, processual e que se contraponha as desigualdades sociais vigentes. Entendo que se apropriar de uma língua estrangeira pode, então, contribuir para uma visão mais abrangente de culturas, princípios e visão de mundo, o que impacta diretamente nas interrelações humanas e no psiquismo dos sujeitos. Além disso, aprender uma língua estrangeira é uma forma de lidar com diferentes discursos sem se deixar dominar ou se alienar por diferentes valores simbólicos, é estar aberto à história e à historicidade do que lhe é diferente. É praticar o respeito, a compreensão e a empatia pela outra cultura.

Portanto, repensar o ensino de língua inglesa pela perspectiva da PsicologiaHistórico-Crítica e da Pedagogia Histórico-Cultural pode ajudar professores engajados na luta pela transformação da sociedade a repensar suas práticas pedagógicas, de modo a tornar suas ações direcionadas à instrumentalização dos indivíduos.

\section{Por uma visão de aprendizagem de línguas estrangeiras: humanizar- se, eis a questão!}

Ser ou não ser, essa é que é a questão:

Será mais nobre suportar na mente

As flechadas da trágica fortuna,

Ou tomar armas contra um mar de escolhos

E, enfrentando-os, vencer? Morrer, dormir,

Nada mais; e dizer que pelo sono

Findam-se as dores, como os mil abalos

Inerentes à carne - é a conclusão

Que devemos buscar. Morrer - dormir;

Dormir, talvez sonhar - eis o problema:

Pois os sonhos que vierem nesse sono

De morte, uma vez livres deste invólucro

Revista Moara, n. 54, ago-dez 2019 ISSN: 0104-0944

Recebido em 30/10/2019

Avaliado em 24/11/2019 
Mortal, fazem cismar. Esse é o motivo

Que prolonga a desdita desta vida.

Quem suportara os golpes do destino,

Os erros do opressor, o escárnio alheio,

A ingratidão no amor, a lei tardia,

$\mathrm{O}$ orgulho dos que mandam, o desprezo

Que a paciência atura dos indignos,

Quando podia procurar repouso

Na ponta de um punhal? Quem carregara Suando o fardo da pesada vida

Se o medo do que vem depois da morte -

$\mathrm{O}$ país ignorado de onde nunca

Ninguém voltou - não nos turbasse a mente

E nos fizesse arcar co'o mal que temos

Em vez de voar para esse, que ignoramos?

Assim nossa consciência se acovarda,

$\mathrm{E}$ o instinto que inspira as decisões

Desmaia no indeciso pensamento,

$\mathrm{E}$ as empresas supremas e oportunas

Desviam-se do fio da corrente

E não são mais ação. Silêncio agora!

A bela Ofélia! Ninfa, em tuas preces

Recorda os meus pecados.

Hamlet, ato III, cena 1

(SHAKESPEARE, 2005)

Trago à tona a obra de William Shakespeare - Hamlet - cujo personagem homônimo profere o famoso questionamento existencial "ser ou não ser, essa é a questão!" para refletir sobre a importância de se posicionar diante dos acontecimentos, e, no caso mais específico deste artigo, para pensar as tomadas de ações frente à aprendizagem de língua inglesa.

Como já exposto, o neoliberalismo exerce uma influência direta no cenário educacional brasileiro, uma vez que coloca a escola em "uma posição estratégica em seu projeto de hegemonia para a regulação e o controle social" (PACIEVITCH ET AL, 2008, p. 4611). Tem-se aí, portanto, um projeto social para educação: formar sujeitos funcionais para cumprir as demandas laborais e que sejam responsáveis o suficiente para construir suas habilidades diante de um mercado cada vez mais competitivo. Diante desta lógica de estado mínimo, surge o questionamento: qual a agenda de formação humana que o professor de línguas estrangeiras assume?

Entendo assim como Pistrak (2003, p. 378) que "o trabalho da escola, enquanto base da educação, deve estar ligada ao trabalho social", isto é, a escola deve ser vista 
como um espaço que possibilita o acesso aos conhecimentos historicamente acumulados no percurso da humanidade, de modo que os indivíduos possam, ao mesmo tempo, compreender o lugar que ocupam na sociedade e se engajar em ações propositivas de mudança. Nesse sentido, a escola também assiste as necessidades efêmeras dos indivíduos. Entretanto, o papel da escola e da aprendizagem de línguas estrangeiras vão além: busca-se desenvolver a consciência dos sujeitos para compreender que a realidade não é natural ou dada ao sujeito, mas, sim, um processo meticulosamente pensado e desenvolvido para manter o status quo.

Portanto, estamos diante de uma situação de extrema delicadeza na aprendizagem de línguas, frente à qual o professor precisa se posicionar e estar consciente de suas escolhas: trabalhamos para manutenção do status quo, formando sujeitos para atender a lógica capitalista e, consequentemente, "suportar na mente as flechadas da trágica fortuna" ou trabalhamos para "tomar armas contra um mar de escolhos e, enfrentando-os, vencer?", como questiona Hamlet? Lutamos por uma aprendizagem de línguas focada em aspectos conteudistas, focada unicamente no conhecimento enciclopédico e, por conseguinte, alienador; ou buscamos uma formação de falantes críticos de línguas estrangeiras, visando a transformação dos sujeitos?

Busca-se um processo de ensino-aprendizagem humanizador mesmo tendo consciência de que o caminho é árduo e cheio de obstáculos, mas possibilitador de que todas as classes sociais tenham acesso aos conhecimentos historicamente acumulados ou convive-se com os fantasmas de um trabalho pedagógico irresponsável e estimulador de desigualdades? As decisões aqui tomadas serão de suma importância para o desenvolvimento de um ensino emancipatório ou alienador.

Coadunar-se aos princípios de desenvolvimento humano proposto pela Psicologia Histórico-Cultural e aos fundamentos pedagógicos da Pedagogia HistóricoCrítica podem ser os primeiros passos para superar visões reprodutivistas, acríticas e tecnicistas que pouco podem fornecer subsídios para que os seres humanos alcancem um desenvolvimento para além do imediato, para além do que o contexto lhes oferta. Portanto, ensinar e aprender passam muito distante de se caracterizarem como situações neutras. Preocupar-se com uma educação transformadora é tomar partido, é fazer escolhas que impactarão diretamente a escola, o aluno e a sociedade.

A seguir, passar-se-á às conclusões. 


\section{Considerações finais}

Neste artigo, buscou-se destacar a importância de se aprender a língua inglesa, não pelo seu caráter hegemônico ou pelas possibilidades de ascensão social. Defendese aqui o ponto de vista de Leffa (2016), que afirma que a aprendizagem de uma nova língua

[...] não é um conhecimento a mais que se adquire e que se soma ao que já temos, como se fosse uma mercadoria acrescentada ao patrimônio. O que é estrangeiro e, portanto, estranho a nós, precisa penetrar na nossa intimidade, provocando um entranhamento que mexe na nossa estrutura psicomotora, afetiva, cognitiva e social” (LEFFA, 2016, p. 8)

Entretanto, o que se percebe é que as instituições brasileiras de ensino foram tomadas pelos pressupostos neoliberais, difundindo práticas alienadoras do papel da educação e, no caso deste estudo, a aprendizagem de línguas estrangeiras. A língua inglesa nesta perspectiva segue a lógica de mercado, tornando-se um privilégio, um bem que tem preço, mas não tem valor humanizador. A competição por quem oferece o melhor curso, o melhor custo-benefício para aprender uma língua estrangeira supera a necessidade de transformação social.

Em face à essa problemática buscou-se na Psicologia Histórico-Cultural e na Pedagogia Histórico-Crítica elementos que propiciassem a reflexão sobre a aprendizagem de língua inglesa, superando assim, uma visão de aprendizagem de línguas simplista, monopolizadora, cruel e excludente. A pedagogia revolucionária idealizada por Saviani (2008) é um importante constructo para se repensar o ensino de língua inglesa comprometido com a transformação da sociedade, de modo a instrumentalizar os indivíduos para as práticas mais elevadas do desenvolvimento humano assim apresentados na Psicologia Histórico-Cultural.

Repensar a aprendizagem de línguas estrangeiras por tais aportes teóricos é uma forma de contribuir para o processo educacional, permitindo que outros professores venham a se objetivar desses constructos teóricos, a fim de superar por incorporação um conjunto de práticas pedagógicas que, porventura, não favoreçam a emancipação dos sujeitos. Aprender uma nova língua abre a visão de mundo dos aprendizes para 
diferentes perspectivas, além de assumir uma função interdisciplinar, facilitando o acesso a diferentes tipos de saberes, além de praticar a reflexão, a criticidade, o respeito por diferentes formas de se relacionar com a história e historicidade humana.

Para que possamos pensar a aprendizagem de língua inglesa para além do capital e dos determinismos impostos pelo projeto neoliberal na educação, o papel assumido pelos professores é de suma importância, visto que são justamente esses profissionais os responsáveis por exercer o trabalho intelectual que irá contribuir para que outros seres ascendam conscientemente por meio do conhecimento. Para ser reconhecido como agente de mudança e não reprodutor de valores excludentes, o professor deve se comprometer com uma agenda de formação humanizadora, empenhada em colocar a aprendizagem de língua estrangeira a serviço da transformação das relações sociais e da emancipação das correntes que alienam os indivíduos.

\section{Referências bibliográficas:}

ARRIGHI, G. O Longo Século XX. Rio de Janeiro: Contraponto/Editora UFRJ, 1996.

BOHN, H. I. O método "soberano" para o ensino e aprendizagem da língua inglesa. In: LIMA, D. C. (org.). Ensino e aprendizagem de língua inglesa: conversas com especialistas. São Paulo: Parábola Editorial, 2009, p. 169-78.

CRYSTAL, D. English as a global language. USA: Cambridge University Press, 2012.

DUARTE, N. A individualidade para-si: contribuições a uma teoria histórico-social da formação do indivíduo. 2. ed. Campinas, SP: Autores Associados, 1999.

DUARTE, N. Vigotski e o "aprender a aprender": crítica às apropriações neoliberais e pós-modernas da teoria vigotskiana. Campinas: Autores Associados, 2000.

DUARTE, N. Vigotski e a Pedagogia Histórico-Crítica: a questão do desenvolvimento psíquico. nuances, v. 24, p. 19-29, 2013.

DUARTE, N. Os conteúdos escolares e a ressurreição dos mortos: contribuição à teoria histórico-crítica do currículo. Campinas, SP: Autores Associados, 2016.

FIORI, J.L. O poder global e a nova geopolítica das nações. São Paulo: Boitempo Editorial, 2007.

FRIGOTTO, G. O enfoque da dialética materialista histórica na pesquisa educacional. In: FAZENDA, Ivani C. A. (Org.). Metodologia da pesquisa educacional. 2. ed. São Paulo: Cortez, 1991. p. 69-90. 
GENTILI, P. A falsificação do consenso: simulacro e imposição na reforma educacional do neoliberalismo no contexto da globalização. Petrópolis: Vozes, 1998.

LEFFA, V.J. Língua estrangeira: ensino e aprendizagem. Pelotas: EDUCAT, 2016.

LEONTIEV, A. N. (2004). O desenvolvimento do psiquismo. São Paulo: Centauro.

MARRACH, S. A. Neoliberalismo e Educação. In: GUIRALDELLI JUNIOR, P. (Org.). Infância, Educação e Neoliberalismo. São Paulo: Cortez, 1996. p. 42-56.

MARTINS, L. M. Contribuições da psicologia histórico-cultural para a pedagogia histórico-crítica. Revista HISTEDBR On-Line, 13(52), 286-300, 2013.

MARTINS, L.M. A internalização de signos como intermediação entre a psicologia histórico-cultural e a pedagogia histórico-crítica. Germinal: Marxismo e Educação em Debate, v. 7, p. 31-46, 2015.

MARTINS, L.M. O desenvolvimento do pensamento e a educação escolar: etapas da formação de conceitos à luz Leontiev e Vigotski. Fórum Linguístico, Florianópolis, v. 13, n. 4, p. 1572-1586, out./dez. 2016.

MARX, K. O Capital. Crítica da economia política. Livro 1 - O processo de produção do capital. Vol. 1, Tradução de Reginaldo Sant'Anna. 15 ed. Rio de Janeiro: Bertrand Brasil, 1996.

MCCHASNEY, R.W. Introdução. In: CHOMSKY, N. O lucro ou as pessoas? Neoliberalismo e ordem global. Tradução: Pedro Jorgensen Júnior. Rio de Janeiro: Bertrand Brasil, 2002. Disponível em: http://bibliotecadigital.puc-campinas.edu.br/services/ebooks/Noam\%20Chomsky-1.pdf. Acesso em 20/09/2019.

MÉSZÁROS, I. A educação para além do capital. São Paulo, Boitempo, 2005.

PACIEVITCH, T.; MOTIN, G.; MESQUIDA, P. O mercado da pedagogia e a pedagogia de mercado: reflexos do neoliberalismo sobre a educação. VIII CONGRESSO NACIONAL DE EDUCAÇÃO - EDUCERE, 2008.

RITZER, G. The McDonaldization of Society. New York: Pine Forge Press, 1993.

SAVIANI, D. Escola e democracia. 32ed. Campinas: Autores associados, 1999.

SAVIANI, D. Pedagogia histórico-crítica: primeiras aproximações. 10. ed. rev. Campinas: Autores Associados, 2008.

SAVIANI, D; DUARTE, N. Prefácio. In: SAVIANI, D.; DUARTE, N. (orgs.) Pedagogia histórico-crítica e luta de classes na educação escolar. Campinas: Autores Associados, 2012, p. 1- 11.

SAVIANI, D. Pedagogia Histórico-Crítica primeiras aproximações. 11.ed. Campinas: Autores Associados, 2013.

TRUCHOT, B.S. L’Anglais dans le Monde Contemporain. Le Robert, Paris, 1990.

VYGOTSKY, L. S. Pensamento e linguagem. São Paulo: Martins Fontes, 1987.

Revista Moara, n. 54, ago-dez 2019 ISSN: 0104-0944

Recebido em 30/10/2019

Avaliado em 24/11/2019 
VYGOTSKY, L. S. \& LURIA A. R. (1996). Estudos sobre a História do Comportamento: símios, homem primitivo e criança. Porto Alegre: Artes Médicas. 